\title{
The reliability of methicillin sensitivity tests on four culture media
}

\author{
D. F. J. BROWN AND D. KOTHARI \\ From the Division of Hospital Infection, Clinical Research Centre, Harrow, Middlesex, and \\ the Cross-Infection Reference Laboratory, Central Public Health Laboratory, London
}

SYNOPSIS The influence of culture medium, incubation temperature, and antibiotic content on the $\mathcal{N}_{\mathrm{V}}$ reliability of methicillin disc-sensitivity tests on strains of Staphylococcus aureus was evaluated. ir Tests were performed with an inoculum giving semiconfluent growth of colonies on four media, $\vec{N}$ with $5-\mu \mathrm{g}$ and $10-\mu \mathrm{g}$ methicillin discs at incubation temperatures of 30,35 , and $37^{\circ} \mathrm{C}$. With Sensitest agar and Mueller-Hinton agar at $35^{\circ} \mathrm{C}$ or below, methicillin resistance was reliably detected. On DST agar and Wellcotest agar discrimination between sensitive and resistant strains was $\overrightarrow{3}$ possible only at $30^{\circ} \mathrm{C}$. On Wellcotest agar and DST agar it was not possible to detect methicillin resistance in one resistant strain at any temperature. For sensitive and resistant strains, the use of $\vec{\varphi}$ a $5-\mu \mathrm{g}$ disc allowed greater differentiation than the $10-\mu \mathrm{g}$ disc.

The difficulties in detecting resistance to methicillin and other penicillinase-stable penicillins in strains of Staphylococcus aureus are well documented. Methicillin is the drug of choice for testing this group of penicillins as tests with cloxacillin and flucloxacillin have been shown to be unreliable (Hewitt, Coe, and Parker, 1969). Populations of methicillin-resistant Staphylococcus aureus show marked heterogeneity in their resistance to methicillin (Chabbert, Baudens, Acar, and Gerbaud, 1965; Knox, 1961). On ordinary nutrient media at $37^{\circ} \mathrm{C}$ resistant cells grow relatively slowly in the presence of methicillin (Seligman, 1966) so resistance may not be detected. Resistance is more reliably detected by incubating tests at $37^{\circ} \mathrm{C}$ for 48 hours, by using a medium containing $5 \% \mathrm{NaCl}$ (Barber, 1964; Churcher, 1968) and incubating tests overnight at $37^{\circ} \mathrm{C}$, or by incubating tests at $30^{\circ} \mathrm{C}$ (Annear, 1968; Hallander, Laurell, and Dornbusch, 1969; Hewitt et al, 1969). A heavier inoculum may also be used. In routine microbiology such additional tests are inconvenient. It would be advantageous if methicillin-sensitivity tests could be performed by the same method as tests of sensitivity to other antibiotics. Drew, Barry, O'Toole, and Sherris (1972) investigated this possibility for the Kirby-BauerSherris-Turck sensitivity-test method and found that incubation of tests at $35^{\circ} \mathrm{C}$ allowed reliable detection of methicillin resistance. Similar results were

Received for publication 5 March 1974. reported by Thornsberry, Caruthers, and Baker (1973).

We have noticed considerable difference in zone size when methicillin-sensitivity tests on methicillinresistant strains of Staph. aureus were performed on different sensitivity-testing media. The purpose of this study was to investigate the reliability of methicillin-sensitivity tests performed at different temperatures on media recommended for sensitivity testing. Mueller-Hinton medium was recommended in the report of an international ccllaborative study on antibiotic sensitivity testing (Ericsson and 8 Sherris, 1971). Wellcotest agar, DST agar, and $₹$ Sensitest agar are made specifically for antibiotic 은 sensitivity testing. The reliability of $5-\mu \mathrm{g}$ and $10-\mu \mathrm{g} D$ methicillin discs for demonstrating methicillin resistance was also compared.

\section{Materials and Methods}

Tests were performed on $\mathbf{3 0}$ methicillin-resistant and 0 15 methicillin-sensitive strains of Staph. aureus. Of the resistant strains 15 were supplied by the Central Public Health Laboratory, Colindale, seven by $\mathrm{Dr} \stackrel{\oplus}{+}$ J. G. Kensit, and five by Mr J. H. Hewitt. Nine of 7 the sensitive strains were supplied by the Central Public Health Laboratory, Colindale. Other strains were from the Department of Microbiology, Northwick Park Hospital, Harrow. All the resistant strains and 11 of the sensitive strains were penicillinase producers. 
All tests were performed simultaneously on Mueller-Hinton agar (Difco), Diagnostic Sensitivity test agar (Oxoid), Sensitest agar (Oxoid), and Wellcotest sensitivity test agar (Wellcome).

Minimum inhibitory concentrations (MICs) of methicillin were determined by the agar-dilution method. Doubling dilutions of methicillin were prepared in the different media. A multiple inoculator was used to spot suspensions of the organisms on the agar. The inocula were prepared by diluting overnight broth cultures of the organisms in sterile distilled water to give semiconfluent growth within the spots. After incubation at $30^{\circ} \mathrm{C}$ for 18 hours the MIC was read as the lowest concentration of methicillin completely inhibiting growth.

For disc-sensitivity tests 9-cm Petri dishes were used containing medium to a depth of $4 \mathrm{~mm}$; the medium was dried and flooded with a suspension of organisms diluted to a density giving semiconfluent growth on the plate. The surface of the medium was allowed to dry before 5- $\mu \mathrm{g}$ and $10-\mu \mathrm{g}$ methicillin discs (Oxoid) were applied. Replicate sets of tests were incubated immediately at 30,35 , and $37^{\circ} \mathrm{C}$ for 18 hours. Zone diameters were measured with sliding calipers, the zone edge being the point of complete inhibition of growth. Where small or minute colonies were present up to the disc within a zone of inhibition no zone was recorded.

\section{Results}

On each of the four media all the resistant strains had MICs of $8 \mu \mathrm{g} / \mathrm{ml}$ or higher, whereas sensitive strains had MICs of $4 \mu \mathrm{g} / \mathrm{ml}$ or below. Correlation of the MIC of methicillin (determined at $30^{\circ} \mathrm{C}$ ) with zone size (5- $\mu \mathrm{g}$ and $10-\mu \mathrm{g}$ discs) at 30,35 , and $37^{\circ} \mathrm{C}$ on the four media is shown in figures $1-4$.

On all media, zones of inhibition of resistant strains were smaller when the temperature of incubation was lower, whereas the temperature of incubation did not significantly affect the zone sizes of sensitive strains. Often the zone diameters of resistant strains were reduced by the growth of smaller colonies within the zones.

Significant differences were apparent between the different media. At all incubation temperatures zone sizes of resistant strains were smaller on Sensitest and Mueller-Hinton than on Diagnostic sensitivity test (DST) and Wellcotest sensitivity test (WST) media. For example, in tests with a $10-\mu \mathrm{g}$ disc and an incubation temperature of $30^{\circ} \mathrm{C}$, all 30 resistant strains gave no zone on Sensitest and Mueller-Hinton agars, whereas 12 strains gave zones up to $16.2 \mathrm{~mm}$ on DST and seven strains gave zones up to $16.5 \mathrm{~mm}$ on WST. One resistant strain gave zones of $23 \mathrm{~mm}$ and $25 \mathrm{~mm}$ on DST and
WST respectively while on $\mathrm{MH}$ and Sensitest colonies were evident up to the disc. Under the same conditions sensitive strains gave zones greater than $20 \mathrm{~mm}$ on DST, Sensitest, and Mueller-Hinton, and greater than $23 \mathrm{~mm}$ on WST.

Zone diameters of sensitive strains were generally about $4 \mathrm{~mm}$ smaller with a $5-\mu \mathrm{g}$ disc than with a $10-\mu \mathrm{g}$ disc. Zones of resistant strains were generally considerably smaller when a $5-\mu \mathrm{g}$ disc was used. Often no zone was present with a $5-\mu \mathrm{g}$ disc when zones of about $15 \mathrm{~mm}$ were measured around a $10-\mu \mathrm{g}$ disc. For example, on DST at $30^{\circ} \mathrm{C}, 12$ resistant strains gave zones of 10 to $16 \mathrm{~mm}$ with a $10-\mu \mathrm{g}$ disc while only two of these strains gave any zone at all with a $5-\mu \mathrm{g}$ disc.

\section{Discussion}

Because of the heteroresistance of methicillinresistant strains of Staphylococcus aureus, any strain with an MIC of methicillin greater than $4 \mu \mathrm{g}$ per $\mathrm{ml}$ was considered to be resistant. Ideally the disc-sensitivity test should clearly distinguish between sensitive and resistant strains. On Sensitest and Mueller-Hinton agars the ideal was most closely attained. Even at $37^{\circ} \mathrm{C}$ with $10-\mu \mathrm{g}$ discs the largest zones with resistant strains were $3 \mathrm{~mm}$ smaller than the smallest zones with any of the sensitive strains. Such resolution was not obtained on DST and WST agars except at $30^{\circ} \mathrm{C}$ and one resistant strain gave zones as large as sensitive strains on these media. The reason for such differences between the media is not clear, but differences in osmolarity and differences in the availability of substrates affecting the resistance mechanism are probably involved.

Comparison of zone sizes with $10-\mu \mathrm{g}$ and $5-\mu \mathrm{g}$ discs showed a greater difference in zone size with resistant than with sensitive strains. Consequently the $5-\mu \mathrm{g}$ disc provided a clearer distinction between sensitive and resistant strains than the $10-\mu \mathrm{g}$ disc, which is most commonly used for methicillinsensitivity testing at present. Drew et al (1972) showed that methicillin discs were less stable on storage than two other penicillinase-stable penicillins, oxacillin and nafcillin. They also found that both oxacillin and nafcillin distinguished more clearly than methicillin between sensitive and resistant strains. Thus tests may prove more reliable using oxacillin or nafcillin discs.

Of the four media methicillin tests on Sensitest and Mueller-Hinton agars can be reliably performed at $35^{\circ} \mathrm{C}$, preferably with a $5-\mu \mathrm{g}$ methicillin disc. Under these conditions a zone of $14 \mathrm{~mm}$ or less on Sensitest and 13 or less on MH may be interpreted as resistant. This interpretation allows some margin for error caused by slight fluctuation in temperature, 


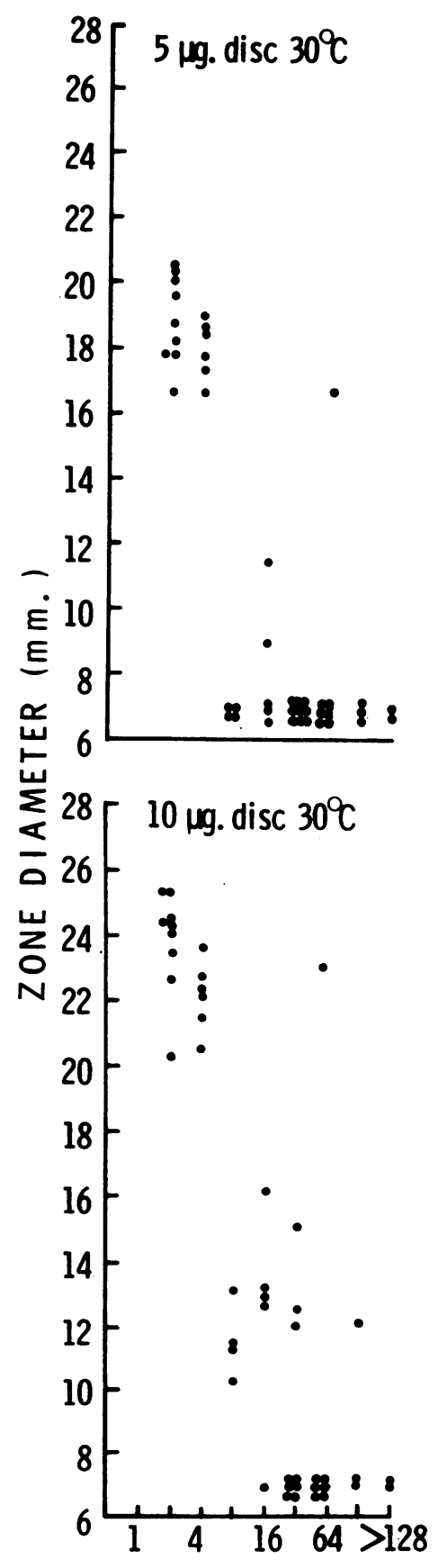

$5 \mu \mathrm{g}$. disc $35{ }^{\circ} \mathrm{C}$

$5 \mu \mathrm{g} . \operatorname{disc} 37 \mathrm{C}^{\circ}$

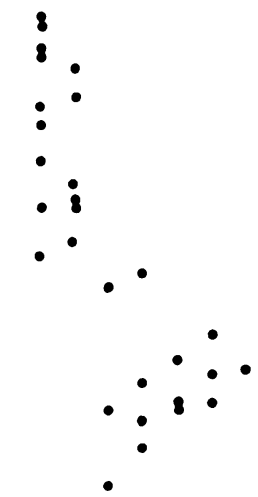

- $8 \div 8$

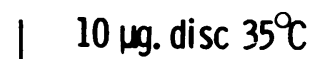

$10 \mu$ g. disc $37^{\circ} \mathrm{C}$
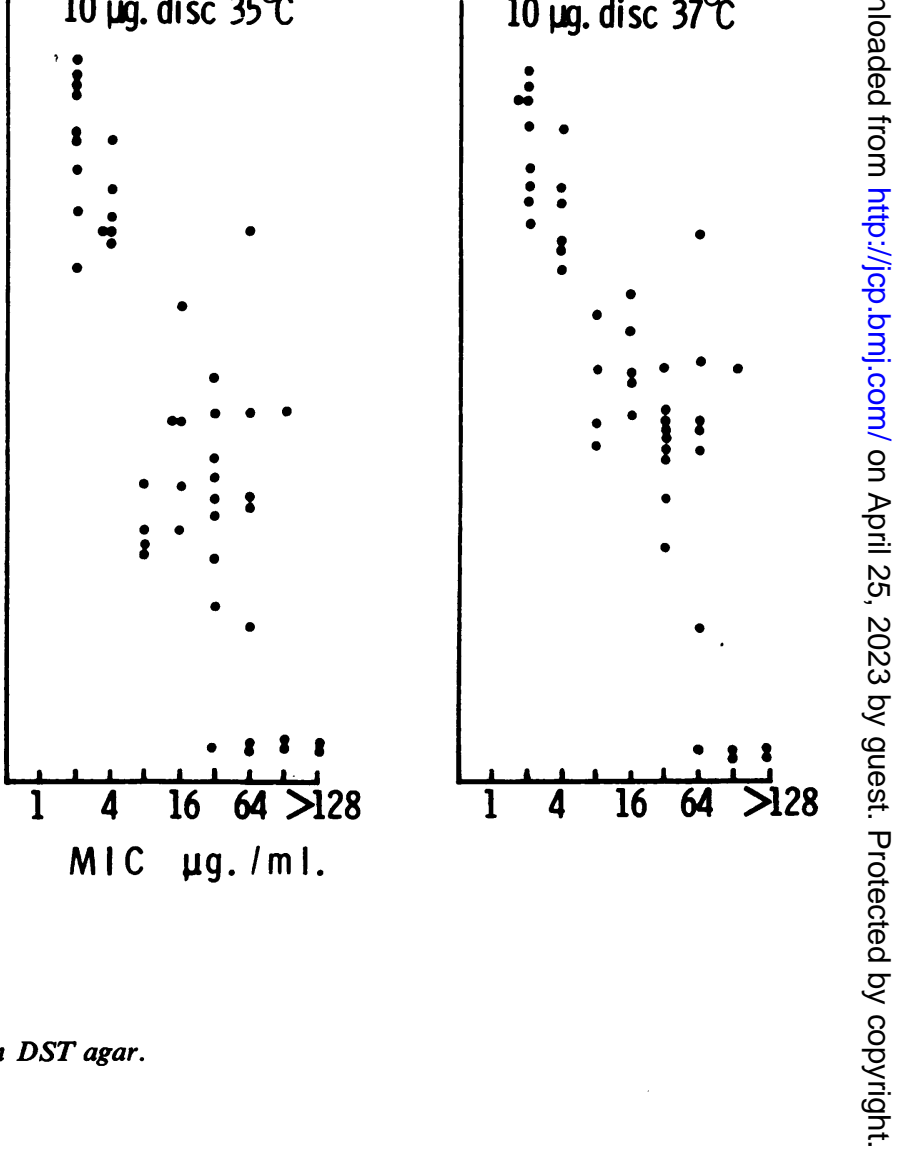

Fig 1 Relationship of zone diameter to MIC on DST agar. 

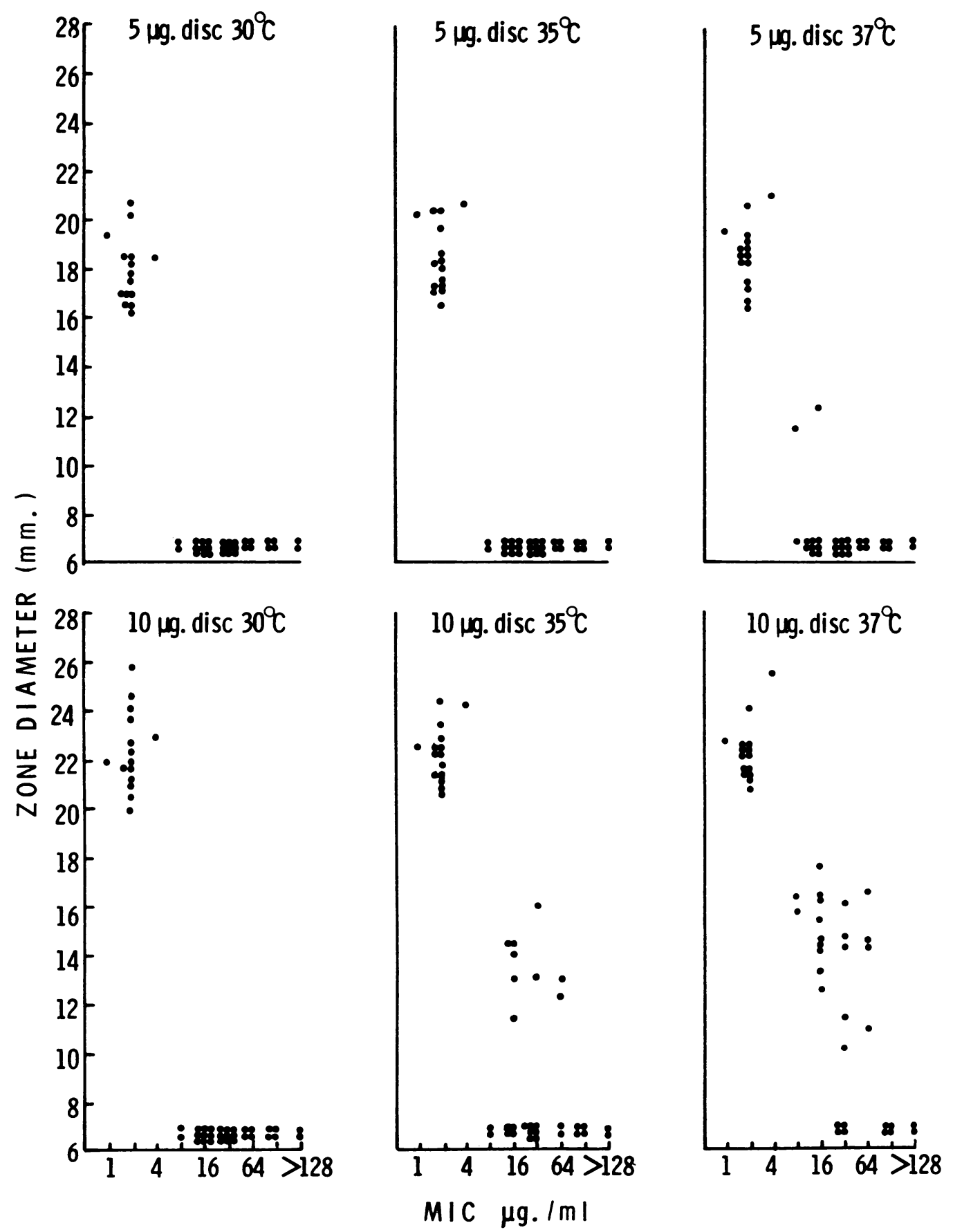

Fig 2 Relationship of zone diameter to MIC on Sensitest agar. 


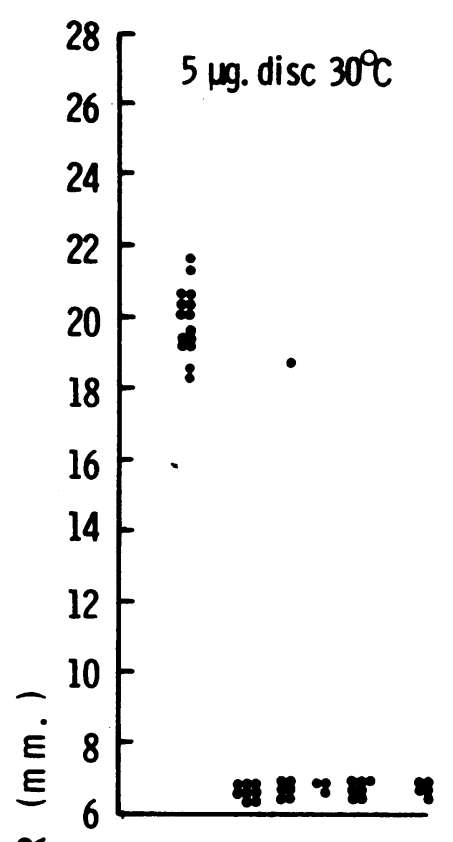

5 mg. disc $35^{\circ} \mathrm{C}$

$5 \mu \mathrm{g} . \mathrm{disc} 37 \mathrm{C}$

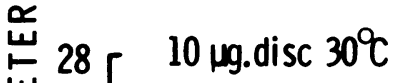

78 $8 \%$

$1818 \%$

$10 \mu \mathrm{kg}$ disc $35^{\circ} \mathrm{C}$
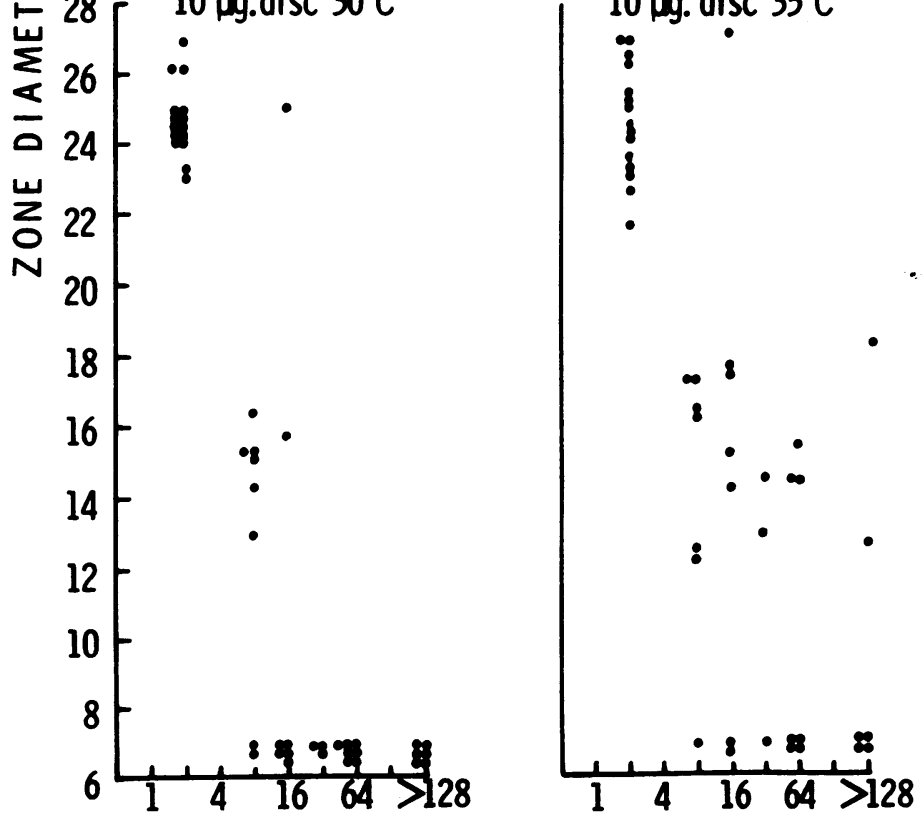

. $10 \mu g$. disc $37^{\circ} \mathrm{C}$

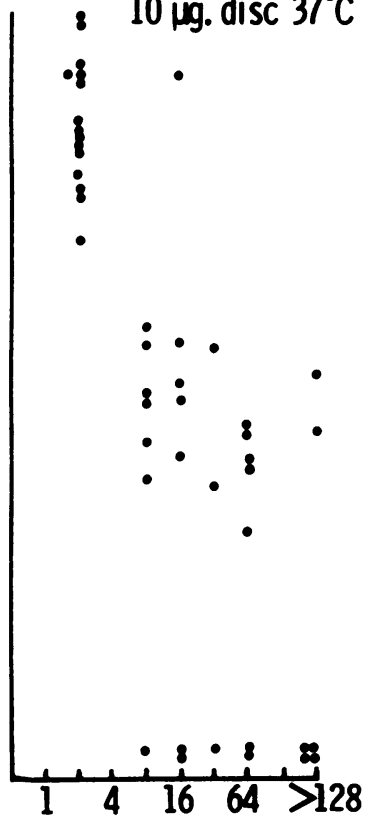

$M I C \mu g . \mid \mathrm{mI}$.

Fig 3 Relationship of zone diameter to MIC on Wellcotest agar. 

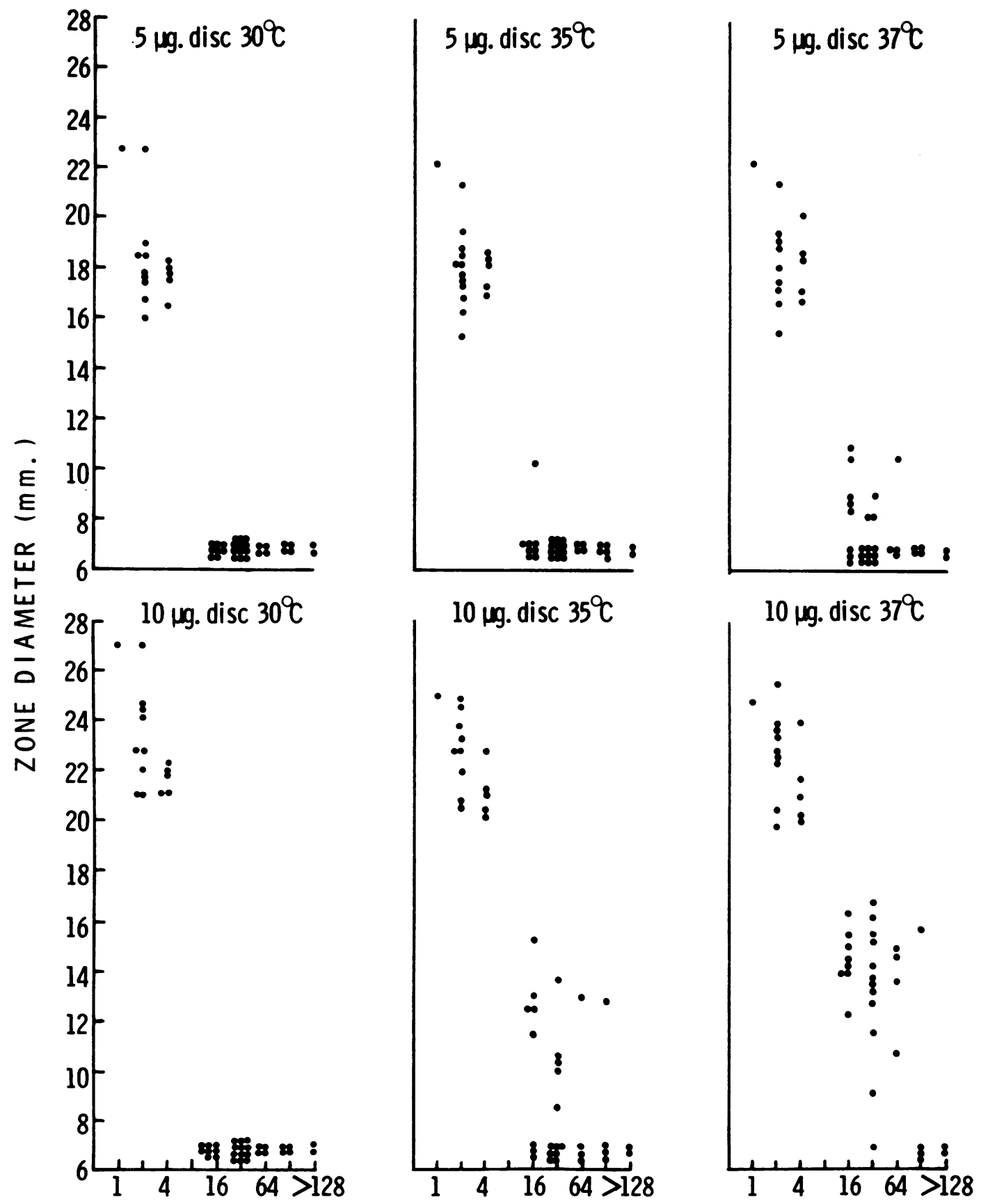

MIC $\mu \mathrm{g} . / \mathrm{mI}$.

Fig 4 Relationship of zone diameter to MIC on Mueller-Hinton agar. 
density of inoculum, and differences in reading between technicians because strains rarely give zone sizes close to these measurements. Using Sensitest agar or Mueller-Hinton agars and incubating antibiotic-sensitivity tests at $35^{\circ} \mathrm{C}$ the inconvenience of separate tests for detection of methicillin resistance would be avoided.

We are grateful to $\mathrm{Dr} \mathrm{R}$. Blowers for helpful criticism, Mr Paul Darton for preparing the figures, and Miss Jeanette Parsons for preparing the manuscript.

DB is a member of the staff of the Central Public Health Laboratory, Colindale, on secondment to the Clinical Research Centre.

\section{References}

Annear, D. I. (1968). The effect of temperature on resistance of Staphylococcus aureus to methicillin and some other antibiotics. Med. J. Aust., 1, 444-446.
Barber, M. (1964). Naturally occurring methicillin-resistant staphylococci. J. gen. Mierobiol., 35, 183-190.

Chabbert, Y. A., Baudens, J. G., Acar, J. F., and Gerbaud, G. R. (1965). La resistance naturelle des staphylocoques a la methicilline et l'oxacilline. Rev. franc. Etud. clin. biol., 10, 495-506.

Churcher, G. M. (1968). A screening test for the detection of methicillin-resistant staphylococci. J. clin. Path., 21, 213-217.

Drew, W. L., Barry, A. L., O'Toole, R., and Sherris, J. C. (1972) Reliability of the Kirby-Bauer Idiffusion method for detecting methicillin-resistant strains of Staphylococcus aureus. Appl. Microbiol., 24, 240-247.

Ericsson, H. M., and Sherris, J. C. (1971). Antibiotic sensitivity testing. Report of an International Collaborative Study. Acta path. microbiol. Scand., Sect. B., Suppl. 217.

Hallander, H. O., Laurell, G., and Dornbusch, K. (1969). Determination of methicillin resistance of Staphylococcus aureus: heterogeneity and its influence on the disc diffusion method. Scand. J. infect. Dis., 1, 169-174.

Hewitt, J. H., Coe, A. W., and Parker, M. T. (1969). The detection of methicillin-resistance in Staphylococcus aureus. J. med. Microbiol., 2, 443-456.

Knox, R. (1961). Correspondence. Brit. med. J., 1, 126.

Seligman, S. J. (1966). Methicillin-resistant staphylococci. Genetics of a minority population. J. gen. Microbiol., 42, 315-322.

Thornsberry, C., Caruthers, J. Q., and Baker, C. N. (1973). The effect of temperature on the in vitro susceptibility of Staphylococcus aureus to penicillinase-resistant penicillins. Antimicrob. Agents and Chemother., 4, 263-269. 